\section{UTOPÍAS Y DISTOPÍAS DE LOS MEDIOS DIGITALES PARA LA EDUCACIÓN}

\section{Alfonso Cuadrado Alvarado}

\section{Profesor Titular Interino}

Facultad de Ciencias de la Comunicación. Universidad Rey Juan Carlos. Campus de Fuenlabrada. Camino del molino s/n. 28943 Fuenlabrada, Madrid (España) - Tlfn.: 914888699 - Email: alfonso.cuadrado@urjc.es

\section{Resumen}

Los discursos que rodean a los medios digitales aplicados a la educación se polarizan en torno a dos visiones, una utópica y otra distópica. Estas manifestaciones influyen en su aceptación o rechazo mucho más que sus empíricas ventajas o inconvenientes de aplicación en el entorno educativo. En el origen de esta visión se encuentran las mitologías que rodearon al nacimiento de la realidad virtual, con su profecía de un nuevo espacio de liberación o de engaño virtual. Esta doble imagen tiene dos sentidos, uno positivo que subyace en las tecnologías digitales para la docencia: el libro viviente como tecnología flexible y fuente de conocimiento autónomo e ilimitado. Y otro negativo, el uso pervertido de la realidad virtual como simulacro alienante, de la mano de los metaversos y los videojuegos que miméticamente simulan la vida real. El desprestigio de la mimesis, en este caso digital, es una actitud que ya encontramos en Platón y que ha permanecido inalterable durante siglos reproduciéndose en la admonición contra diversas tecnologías y formatos (libros, cine, comic, televisión, internet). Este artículo define los modelos imaginarios sobre los que se apoyan los discur-
Palabras clave

Medios digitales, videojuegos, internet, educación, realidad virtual

Key Words

Digital media, video games, internet, education, virtual reality

\footnotetext{
Abstract

It is not often analyze the discourses surrounding digital media applied to education which concentrate on two views, a utopian and a dystopian and influence their acceptance or rejection

far more than the reality of their actual implementation. The origin of this view are the myths surrounding

the birth of virtual reality, with its prophecy of a new space of liberation.

This double image has two meanings, one positive influenced by the theory of hypertext and the concept of living book and an instrument of self-

knowledge and unlimited. And another negative muted the positive uses of the metaverse and simulation game pitting real life.
} 
sos de las nuevas tecnologías educativas y sus antecedentes en el marco de la cibercultura.

\section{Introducción}

Todo discurso sobre los usos educativos de las tecnologías digitales, sea realizado en un entorno académico, divulgativo, empresarial o político, lleva aparejado en mayor o menor medida, una serie de connotaciones que le tiñen de un barniz ideológico que tiende a ver las tecnologías de una forma positiva o negativa, utópica o distópica. A la larga ese discurso condiciona el diseño, comercialización y uso de esas tecnologías que realizan tanto los especialistas como el gran público.

Estos discursos sobrepasan las meras disciplinas tecnológicas para entrar en un terreno que bebe de las percepciones culturales de la tecnología (Thornton Caldwell, 2000), lo que se denomina imaginarios sociales. La sociedad se cohesiona a través de una compleja red de significados que permiten dirigir las acciones colectivas e individuales, un conjunto de significados sociales que se encarna en hechos y materiales culturales así como en instituciones públicas. Pero el imaginario social no es la representación de ningún objeto o sujeto:

El imaginario no existe a partir de la imagen en el espejo o en la mirada del otro. Más bien 'el espejo' mismo y su posibilidad, y el otro como espejo, son obras del imaginario, que es creación ex nihilo... El imaginario del que hablo no es imagen de... es creación incesante y esencialmente indeterminada (social-histórica-psíquica) de figuras/formas/imágenes, y sólo a partir de éstas puede tratarse de 'algo'. Lo que llamamos 'realidad' y 'racionalidad' son obras de esta creación. (Castoriadis, 1993: 29)

El ordenador, internet, los teléfonos móviles, los videojuegos o los mundos virtuales se nos presentan como la nueva tierra de promisión del siglo XXI o el nuevo infierno: simulacros, terrenos incontrolables para la delincuencia a través de la red, delitos sexuales o nuevas adicciones generadas frente a la pantalla del ordenador o de las videoconsolas. Estos imaginarios de las nuevas tecnologías se configuran como universos que se mantienen en un segundo plano y que hablan por nosotros sin que seamos conscientes de ello. Desentrelazar la maraña de los discursos que rodean a las tecnologías digitales es una labor fundamental para cualquier análisis de la cultura digital, especialmente en un momento como el actual donde se "funden las fronteras entre digitalización de la cultura y la cultura digital”. (Alsina, 2010: 2). 


\section{Objetivos}

- Revelar los antecedentes de los discursos que rodean a las tecnologías digitales para la educación, bipolarizadas en torno a las manifestaciones utópicas y distópicas que tienen su origen en la visión de la realidad virtual y en las tensiones que atraviesan la representación hiperrealista de los medios audiovisua- les y digitales frente a las corrientes antimiméticas heredadas de Platón.

- Plantear como punto de partida para futuros trabajos, los posibles interrogantes que los discursos sobre la tecnología encubren en cuanto a sus implicaciones, diseño o utilización industrial o educativa.

\section{Metodología}

Para alcanzar estos objetivos se parte de la base que un estudio del discurso de las nuevas tecnologías sobrepasa el ámbito propio de su actuación y entra en la literatura, el cine, el arte y los textos de divulgación sobre la realidad virtual, por lo que se realiza una exposición descriptiva de textos de estos campos, que busca figura- ciones, formas e imágenes que dan sentido a la visión que se presenta de la tecnología para la educación. Se establece un recorrido por las principales visiones de la tecnología cultural desde la tecnofília y tecnofobia hacia los medios de comunicación de masas hasta los mitos de la cibercultura.

\section{Las tecnofantasías de los medios digitales}

El imaginario sobre medios digitales es bidireccional: distópico y utópico, partiendo ambas visiones de un mismo concepto, las tecnofantasías, que se constituyen como:

Un imaginario que se basa en el cruce entre las posibilidades de las nuevas tecnologías y el deseo humano, el orden social (entendido éste en su sentido más amplio como conjunto de normas y creencias que fundamentan la convivencia de un grupo) y la identidad personal (Ihde, 2004:15).

El desarrollo tecnológico no es armónico ni dúctil. La invención o el descubrimiento hace acto de presencia en la sociedad ofreciendo por un lado una nueva puerta hacia algo liberador que se vislumbra con mayor o menor difusión y por otro poniendo en crisis un modelo estable de orden y/o conocimiento que impera como norma en la sociedad. Esta fractura de lo conocido 
provoca la bipolaridad entre la demonización que conlleva la distopía, que no es otra cosa que la resistencia y el miedo a lo desconocido, y la utopía más o menos fantasiosa o hábilmente dirigida tras intereses políticos o industriales que glorifica y eleva la tecnología como panacea para los problemas sociales o nuestras limitaciones físicas. Tales posturas generan un corpus de textos, manifestaciones públicas realizadas por comunicadores, científicos o políticos, u obras de ficción donde se manifiestan las diferentes visones de la repercusión de la tecnología en la sociedad. Esta producción de literatura admonitoria o defensiva suele alejarse de la estricta y rigurosa documentación científica, y acerarse más a la prospectiva y a la ficción más ensoñadora, formando lo que hemos denominado tecnofantasías.

¿Cuáles son las tecnofantasías sobre el discurso de las tecnologías digitales para la educación? Básicamente existen dos figuraciones que se proyectan utópica y distópicamente: el libro viviente como universo virtual didáctico y el videojuego como reverso antieducativo del libro, respectivamente. Para entender sus características es necesario previamente que veamos el tronco común del que parten, un tronco que hunde sus raíces en las reacciones frente a la industrialización, que pasa por la contestación ideológica en la posguerra hacia el imperialismo de los nuevos medios y que converge en los mitos del ciberespacio y la realidad virtual.
Mucho antes de que las tecnologías digitales irrumpieran no sólo en el escenario académico sino también en el industrial, se produjo un extenso debate sobre el papel de la tecnología en la nueva cultura de los medios. Es el debate que Umberto Eco supo sintetizar bajo el ya universal binomio apocalípticos frente a integrados (Eco, 2004). Los apocalípticos consideraron entonces (mediados del siglo XX) la cultura de masas y las tecnologías que las propiciaban, antihumanas, degradantes del arte y herederas de los efectos perniciosos de la sociedad industrial.

La excesiva automatización, la pérdida de lo humano y el saber artesanal frente al poder y estandarización industrial, eran argumentos de los apocalípticos que recordaban viejas figuraciones como la del robot o el autómata amenazante que habían poblado muchas de las ficciones más exitosas de la literatura, el teatro o el cine. En definitiva, la imagen de la máquina derrotando al hombre y su civilización.

Por el contrario, los integrados exaltaban las nuevas posibilidades de los medios de comunicación, su espíritu democrático y su capacidad para poner al alcance de nuevos públicos información, arte y cultura.

Entre los apocalípticos cabe destacar nombres como Adorno o Marcuse y entre los integrados la figura de McLuhan.

Apocalípticos e integrados se reinventan en la siguiente generación que impulsará las tecnologías digitales. Los nuevos integrados 
tomarán de la literatura de ciencia ficción las visiones del ciberespacio como un terreno de promisión donde la tecnología se aliará con el progreso e incluso dará lugar a una nueva socialización democrática que nos traerá software e información libre para todos. La puerta al edén digital será la realidad virtual y el ciberespacio su geografía. Rheingold, Lanier o Negroponte son algunos de los primeros profetas de la nueva religión digital.

El periodista Howard Rheingold teñía la descripción de una de sus primeras experiencias con realidad virtual de un carácter de revelación religiosa:

En la Universidad de Carolina del Norte tuve una experiencia transformadora, similar a la experiencia que ha cautivado a muchos de los pioneros de los ordenadores personales en los años 1960 y 1970: una visión compulsiva de futuro. Pero esta vez el impulso creador tenía un temor de matiz reverencial (Rheingold, 1994: 15).

Transformación, visión, futuro, temor, son palabras que pertenecen al campo semántico de la conversión, la experiencia religiosa que nos precipita a la caída ante una luz que nos guía en nuevo camino.

Otra de las figuras sobresalientes en las profecías de los nuevos mundos virtuales fue precisamente el creador del término realidad virtual, el americano Jaron Lanier. Joven inconformista, dejó la escuela en su adolescencia para dedicarse al mundo de la música electrónica. De ahí llegó a las com- putadoras y se dedicó, en la próspera industria informática de Silicon Valley de los ochenta, a crear efectos de sonido para los videojuegos. La mística hippie planeaba sobre los grupos de jóvenes que habían viajado a California y diseñaban el futuro en pequeñas comunidades en medio de la naturaleza. Parte de su visión de la realidad virtual se inspira en el romanticismo, el surrealismo y la fascinación por lo oriental de la cultura alternativa de los setenta. A su primer lenguaje de programación lo llamó mandala y llegó a proclamar que la realidad virtual, en su estadio más avanzado se convertiría en un nuevo lenguaje que relegaría el habla y la escritura a un segundo plano. Según Lainer, gracias a las máquinas domésticas de realidad virtual, acabaríamos intercambiando simulacros de nuestras percepciones sensoriales más íntimas en lugar de expresarlas mediante el lenguaje simbólico. Lainer fundaría una de las primeras empresas dedicadas a las tecnologías de la realidad virtual: "VPL. Research, Inc." (Las iniciales corresponden a Virtual Programming Languages).

El término ciberespacio fue introducido por William Gibson, uno de los fundadores de la corriente literaria de ciencia ficción denominada cyberpunk, en su novela Neuromante (Gibson, 2002), considerada como el texto fundacional del movimiento. En ella un "cowboy de consola", sufre un mal que le impide conectarse al ciberespacio y que le impulsa a un viaje en busca de un remedio para su enfermedad. A través de 
ese viaje el autor despliega un universo de humanos que sienten su cuerpo como algo limitado y sin emoción. El verdadero éxtasis se consigue en el ciberespacio, donde se viven experiencias que recuerdan la psicodelia propia de los viajes del LSD. Aunque hay que conceder a Gibson el valor de crear la palabra ciberespacio, como concepto ya fue tratado por otros autores de ciencia ficción como Frederick Pohl o John Varley que ya se habían planteado la posibilidad de una realidad generada por ordenador. ¿Pero qué es el ciberespacio?

El Ciberespacio. Una alucinación consensual experimentada diariamente por billones de legítimos operadores, en todas las naciones, por niños a quienes se enseña altos conceptos matemáticos... Una representación gráfica de la información abstraída de los bancos de todos los ordenadores del sistema humano. Una complejidad inimaginable. Líneas de luz clasificadas en el no espacio de la mente, conglomerados y constelaciones de información. Como luces de la ciudad que se aleja... (Gibson, 2002: 69).

El mundo soñado por Lanier o Gibson presentaba un panorama cotidiano dominado por los simulacros virtuales. El ordenador sería nuestro vínculo constante con la realidad, o lo que quedara de ella, ya que objetos y personas no serían otra cosa que representaciones digitales. En este ambiente seriamos libres para elegir la identidad que quisiéramos, modelarla y cambiarla a nuestra voluntad según las necesidades de la comunicación virtual.

En esta utopía se encuentra implícita una de las más viejas aspiraciones del arte occidental: conseguir un doble indistinguible de la realidad. Desde el perspectivismo renacentista, el ideal de conseguir una copia esencial se ha convertido en el motor que ha hecho evolucionar la tecnología durante varios siglos. Es lo que en la terminología de la técnica contemporánea podemos denominar la búsqueda del hiperrealismo digital.

La fotografía inaugura la edad de los sistemas mecánicos de captación y reproducción de la imagen, tomando el testigo que hasta entonces había llevado la pintura. A partir de entonces y a través de sus herederos (el cine y la televisión) la investigación en las tecnologías digitales se encaminará a ese viejo precepto occidental de la copia esencial, mimética. En esta línea, la realidad virtual sería la culminación de la copia esencial, el doble indistinguible de la realidad. 


\section{El libro viviente}

La interactividad, la libre exploración de los universos virtuales o la posibilidad de la coautoría de ficciones son algunos de los presupuestos de la realidad virtual que serán compartidos por otra corriente que vio en las tecnologías digitales el soporte para materializar las teorías literarias de la estética posmoderna, nos referimos al hipertexto. Apoyado en las teorías de Vannevar Bush sobre la idea de una máquina que gestionara una red de textos interconectados (Bush la llamó Memex) Ted Nelson creó el término hipertexto en 1965 (Nelson, 1992). Etimológicamente se podría decir que el hipertexto es un exceso de texto, un más allá del tradicional texto impreso que se conforma como la naturaleza propia del texto informático. De forma práctica podemos decir que el hipertexto o mejor la hipertextualidad como característica, es la capacidad de asociar una parte de un texto digital con un fragmento de otro de igual naturaleza. Manejar hipertextos o medios que son hipertextuales, es lo que realizamos a diario frente al ordenador cuando hacemos clic en una palabra (generalmente subrayada o resaltada mediante otro color) y el ordenador gracias a la orden que está programada tras la palabra busca un texto determinado sea en ese mismo documento, en otro, en una base de datos o en una dirección web. Las tecnologías digitales cambian por completo el panorama acelerando los procesos, permi- tiendo que el lector acceda fácilmente a gran cantidad e información e incluso convirtiendo a éste en lector-escritor o lectoautor (wreader) debido a que en determinados sistemas digitales en red las modificaciones que el usuario imprime en un hipertexto quedan a disposición de nuevos lectores.

Teóricos como George Landow (1992) o Michael Joyce vencieron la resistencia que la comunidad académica posee tradicionalmente hacia la tecnología y apoyándose en prestigiosos teóricos como Barthes, Derrida o Deleuze elevaron el hipertexto a la categoría de instrumento ideal de conocimiento de la nueva era. La intertextualidad, la lectura fragmentaria y libre, la ruptura de la linealidad narrativa, son características del hipertexto que se convierten en metáforas de la condición contemporánea del sujeto: un ser con libertad para construir su propia red de significados que coexiste e interacciona en un complejo e infinito coro con las de sus semejantes.

La realidad virtual y el hipertexto se aliarán en perfecto maridaje para alumbrar la tecnofantasía utópica más próxima al terreno educativo y del que beben inconscientemente diseñadores y educadores, el libro viviente. Un mito que se apoya en tres pilares: la visión del conocimiento como un universo ilimitado, una geografía del saber (realidad virtual), la posibilidad de una navegación libre por ese conocimiento 
(hipertexto) y una autodirección del aprendizaje (libertad individual).

De nuevo la ciencia-ficción presenta la ensoñación perfecta de ese libro totalmente interactivo que adapta sus contenidos y formas a las necesidades del lector. En $\mathrm{La}$ era del diamante: manual ilustrado para jovencitas (Stephenson, 1997) se nos presenta una futurista ciudad de Shangai donde un rico neovictoriano ordena fabricar un manual informatizado para la educación de su nieta Elizabeth. El manual es completamente interactivo y se adapta automáticamente a las necesidades de su lector. El libro es robado y tras varias peripecias acabará educando a la pequeña Nell, una niña china pobre. Técnicamente Stephenson concibe el hardware del libro como un papel inteligente compuesto de miles de pequeños ordenadores esféricos conectados a través de nanotubos de carbono convirtiendo el papel en un poderoso ordenador gráfico.

En el manual se desarrolla una aventura gráfica cuya protagonista es un doble digital o avatar de Nell. Este doble va adquiriendo habilidades y resolviendo problemas en el mundo de la ficción que utiliza la auténtica Nell para enfrentarse a los conflictos que le van sucediendo en la vida real. La narración no discurre linealmente y permite a la niña real intervenir en el tiempo de lo hechos. $\mathrm{Si}$ la protagonista lee con detenimiento determinados detalles de la acción, ésta crece y se expande en acciones paralelas a partir de estos hechos. Para que el texto del manual se actualice con respecto a los acontecimientos que se viven en la realidad, basta con introducir datos que permitan reconstruir el argumento para que ofrezca líneas y tramas que se correspondan con la experiencia de la niña. A medida que ésta crece, el libro cambia y los ayudantes (eran los dobles de ficción de sus juguetes favoritos) desaparecen y la narración se convierte en un laberinto más enigmático que pone a prueba la capacidad deductiva de la niña.

La fantasía de Stephenson impulsa las profecías sobre las virtudes educativas de las nuevas tecnologías. Aunque creado bajo la más desarrollada nanotecnología, interactivo y personalizable, el manual no deja de ser un libro. Las fantasías de la educación virtual van más allá, buscan la desaparición del objeto clásico como soporte del conocimiento para convertir las materias en mundos tridimensionales con los que pueda interactuar el niño y aprender por si mismo, directamente a través de la realidad. La pionera en el diseño de humanos virtuales Diana Walczak ha visualizado cómo sería este tipo de aprendizaje bajo la denominación de Adventure Learning (Walczak, 2002). Walczak imagina a una niña, Iona (curiosamente como la Nell de La Era del diamante) en el año 2020 que se adentra en un sistema de realidad virtual el Tangitrek, un exoesqueleto que permite tener una percepción sensorial completa. Las imágenes de esta simulación nos muestran como Iona pretende construir un caballo alado 
mediante la manipulación genética. Para ello se sumerge en un modelo de ADN y debe manipular físicamente las proteínas para conseguir la cadena adecuada. Los cambios de paisajes y acciones propuestos recuerdan más al tour de un parque de atracciones que ha una clase tradicional. Ni que decir tienen que la fantasía de Diana Walczak aún está por realizar y depende de una sofisticada tecnología sólo al alcance de entidades de alto nivel.

A partir de este momento la tecnofantasía del libro viviente quedaba consolidada como fuente inspiradora para todas las generaciones posteriores de aplicaciones en el aula de las nuevas tecnologías y el software educativo, un nuevo arsenal tecnológico, con la posibilidad de adaptarse al alumno y permitir que éste desarrolle individualmente en función de sus características la tarea educativa. En definitiva, un sueño de la herramienta educativa moderna, democrática, que difumina además la estructura tradicional de la clase y borra la tiranía de la figura intermedia del profesor.

\section{Posesiones y patologías digitales}

El sueño tiene su lado oscuro en las pesadillas. Y las pesadillas de las nuevas tecnologías serán descritas por los apocalípticos digitales como Virilo (1997) que verán en la realidad virtual un simulacro, con lo que de peyorativo tiene esta palabra, que nos despersonalizará y encantará como nuevo canto de sirenas, hacia una confusión con la realidad tal y como la entendemos hasta ahora. Lo mimético, esa copia esencial perseguida en occidente por la pintura y los medios audiovisuales, llegará entonces a su máximo grado de perversión de la mano de una tecnología que no pretende representar sino engañar.

¿Debemos, según las indicaciones de los apocalípticos digitales, frenar el poder mimético de las tecnologías virtuales? ¿Nos llevarán a la perturbación y confusión? Jean-Marie Schaeffer analiza muy bien el origen del descrédito de la mimesis y las opiniones admonitorias sobre los excesos realistas de la simulación:

La cruzada contra los simulacros se presenta a menudo a la vez como una lucha moral y como una defensa de la excelencia artística, pues se supone que la pulsión mimética es a la vez peligrosa (nos aliena) y fácil (obedece a «recetas»). Por lo tanto, el discurso antimimético es antes que nada un discurso de pedagogo (Schaeffer, 2002: 5).

Y el primer pedagogo que señala Schaeffer fue Platón. Platón considera que la imitación no es una forma de conocimiento (sólo la admite cuando el objeto de imitación es el adecuado), tanto por la forma en que se ha producido como por su modo de ser recibida por el público. La imitación funciona a nivel de lo afectivo (que según él perturba el conocimiento) y no a nivel de 
la razón, la única herramienta válida para tal fin. Schaeffer señala cómo ésta postura es fruto de un proceso de cambio en la sociedad griega en la que se comenzaba a fundar un sistema de creencias basado en el universo de la filosofía, las matemáticas y el saber empírico. El aprendizaje individual basado en la abstracción y las explicaciones conceptuales se empezaba a separar de los relatos modelo, los mitos, con una forma muy distinta de funcionamiento cognitivo.

Siglos después esta condena de lo mimético se ve impulsada por Nietzsche cuando en su obra El nacimiento de la tragedia aporta una explicación sobre el surgimiento de la obra de ficción a partir de la evolución de la encarnación mágica. Según Nietzsche (1997) el origen de la ficción se sitúa en los rituales de posesión donde la mimesis no era vivida como un simulacro sino como una fusión del oficiante con el espíritu sobrenatural. El cuerpo abandonaba su identidad para ser vehículo de una deidad. En este caso el simulacro no es tal y el rito de inmersión y mimesis se vive como una verdad. Cuando el ritual pierde su sentido religioso los procesos miméticos permanecen, contaminando la ficción de la irracionalidad propia de lo mágico.

Despreciar la mímesis, la inmersión y la actividad emotiva que lleva aparejada es, hoy por hoy, reformular sin reflexión alguna las añejas opiniones de Platón y Nietzsche. El placer que produce la inmersión y los resortes afectivos que convocan no excluye la capacidad crítica y reflexiva del lector o espectador. Sostener que la ficción de carácter popular o masivo se sustenta exclusivamente en dichos apoyos, en el simple placer del entretenimiento de la lectura inocente, y que por ello debe ser denostada, es no reconocer el papel fundamental de la representación de las emociones y de la experiencia en el conocimiento por imitación. Buena parte de las conductas individuales y sociales, la transmisión de valores o las respuestas afectivas se inculcan en los individuos a través de la ficción. Y en el caso concreto de la realidad virtual, su objetivo no es provocar un escalofrío siniestro al mostrar un doble de la realidad que nos engañe, al contrario, su valor es más educativo del que se cree ya que como herramienta es mucho más abstracta de lo que su nombre indica (muchos expertos prefieren utilizar los términos entornos virtuales y renunciar a la problemática palabra realidad), teniendo como función crear modelos de sistemas, mundos o procesos, que se elaboran para facilitar su compresión o estudio mediante la experiencia directa del usuario. Pero esta función no siempre es fácil de ver y aceptar.

Las nuevas tecnologías han desarrollado más la capacidad de inmersión del espectador. Su acción consiste en eliminar el máximo de marcadores que permita al usuario separar la ficción de lo factual. Sin duda, ello también ha facilitado el que nuevos contenidos violentos puedan ponerse en acción más intensamente: estereotipos que discriminan sexualmente, estimulación del consumo como 
una nueva forma de violencia, la trivialización de la xenofobia y el racismo o sencillamente, la identificación de la competición (deportiva) y la competitividad (agresiva, dura, violenta). Las redes de ordenadores han creado un espacio, antes conquistado por la televisión, que se sumerge a veces en lo abominable (Contreras, 2001: 169).

En estas palabras encontramos los ecos del miedo a la inmersión digital, que nos hace perder el sentido de la frontera entre realidad y ficción, ese trance del poseso que pierde la razón y doblega su voluntad ante la seducción perversa del nuevo medio. Pero por la puerta de la posesión de la realidad virtual no se cuelan ahora ideologías o cosmovisiones religiosas. Los nuevos demonios (más bien su nueva reformulación) que se enfrentan a la razón son la violencia, el sexo y el racismo. La última frase de la cita es altamente significativa del alegato contra los espacios virtuales generados por el ordenador: nos sumergen en lo abominable. Y lo abominable tiene nombre de juego perverso: los videojuegos.

En el surgimiento de los videojuegos se produjo una coincidencia que los lastraría durante años, su nacimiento en bares y salones recreativos. Aunque el concepto de consola de videojuegos tal y como lo conocemos ahora ya estaba creado en los años setenta, la popularización de esta nueva forma de juego durante la década y hasta bien entrados los ochenta se debe a su implantación junto a otras máquinas ya muy populares y de las que copia su estructura física y la forma de uso. Nos referimos al pinball. El pinball consiste en un mueble decorado con sugerentes y barrocos motivos provenientes del mundo del comic o de series de aventuras o ciencia ficción, en el que una bola se debe impulsar mediante los flippers o pulsadores, para que presione los marcadores y no caiga en el agujero central. Por unas monedas disponemos de varias bolas. El juego nace en los años treinta en Estados Unidos creado por David Gottlieb bajo el nombre de Baffle Ball, que está considerado como el juego originario del pinball. Desde esos años su presencia en bares y salas recreativas es constante y creciente, seduciendo tanto a mayores como a jóvenes. Cuando en los años setenta la recién creada empresa Atari decide popularizar el videojuego de tenis Pong, sus técnicos crean un prototipo bajo el modelo del pinball: un armario de madera donde se introduce un televisor en blanco y negro, la circuitería y el sistema de recepción de monedas. Se probó en un bar de Sunneyvale (California) y el éxito fue arrollador. Había nacido el arcade que poco a poco desplazaría al pinball en las salas recreativas Jugar en una máquina de arcade implicaba tiempo, destreza y dinero. El uso, aunque no el fin, era similar a las tragaperras: desafío contra la suerte o la máquina. Por otro lado las salas recreativas (en España durante años se conocieron popularmente como billares, pues era este juego, anterior a otros de naturaleza eléctrica y electróni- 
ca, el primero que ocupó esto salones) nunca fueron consideradas el lugar más idóneo para la juventud. Se les revestía de cierta aureola de entrada al mundo de la marginalidad (drogas y delincuencia juvenil) y su uso se asociaba con el absentismo escolar. Los videojuegos no nacen en el noble silencio de una biblioteca sino rodeados del humo de los primeros cigarros, el alcohol y la necesidad de dinero para seguir jugando. A esto hay que añadir la temática que les empieza a caracterizar: competiciones deportivas, luchas espaciales, batallas entre monstruos y caballeros medievales, en definitiva nada educativo a priori.

No es de extrañar que naciendo en este ambiente el videojuego arrastre cierto pecado original que veinte años después no sólo no ha expiado sino que ha provocado que en las cajas de los videojuegos aparezcan unos códigos de clasificación que recuerdan el utilizado en décadas anteriores para regular el acceso de menores a las pantallas cinematográficas. Así se vigilará todo juego que contenga escenas de violencia, sexo, que muestre el uso de tabaco o alcohol y utilice blasfemias ${ }^{\mathrm{i}}$.

Educadores, asociaciones de padres y expertos en comunicación verán en el nuevo entretenimiento la continuación de una polémica ya iniciada en los años sesenta en otro medios: la influencia nociva de la televisión en los niños y jóvenes. Las críticas que se hicieron a la pequeña pantalla se extienden ahora al juego interactivo:
1.- El tiempo empleado en ellos es visto en detrimento del dedicado al estudio y como inhibidor de otras actividades de recreo más positivas y "educativas". Los partícipes de esta opinión exponen que podría reforzar el aislamiento social y provocar alienación entre los niños socialmente marginados.

2.- Podría también favorecer una pauta de conducta impulsiva, agresiva y egoísta entre los usuarios más asiduos, sobre todo aquellos que juegan con videojuegos violentos. Incluso se argumenta que podrían predisponer a los niños a aceptar la violencia con demasiada facilidad.

3.- También se argumenta que el juego imaginativo, creativo o de fantasía, así como el desarrollo de habilidades sociales no puede tener lugar mientras se "destruye al enemigo".

4.- Otra razón hace referencia al factor económico. Algunos jugadores gastan el dinero destinado al desayuno en la escuela, en videojuegos, hurtan dinero a sus padres o realizan pequeños robos a fin de conseguir monedas para jugar.

5.- Finalmente la conducta adictiva de estos jugadores podría inhibir el desarrollo de pautas de conducta mas constructivas (especialmente sociales) y podría dar lugar a problemas con el manejo del dinero similares a los de algunos ludópata (Farray, Aguilar, Bonny y Calvo, 2002: 20).

La visión de adolescentes y jóvenes que pasan largas horas delante de las pantallas se creó a raíz de lo que el profesor del MIT 
Joseph Weizenbaum llamó en su libro Computer Power and Human Reason (1969) "bohemios de las computadoras":

Jóvenes brillantes de aspecto desaliñado, con frecuencia con ojos hundidos y brillosos, pueden verse sentados frente a la consola de la computadora, con los brazos tensos y esperando accionar los dedos, ya preparados para atacar las teclas y botones los cuales cautivan su atención como lo hace el movimiento del dado para los jugadores. Cuando no están tan desfigurados, generalmente se sientan a la mesa cubiertos por hojas impresas de computación que leen absortos como poseídos estudiosos de un texto cabalístico. Trabajan hasta que están por caerse, veinte, treinta horas seguidas. Siempre les llevan la comida, si acaso piensan en ella: café, Coca-Cola, bocadillos. Si es posible duermen en catres cerca de las hojas impresas. Su ropa arrugada, cara sin lavar ni afeitar y cabellos despeinados, todo refuerza la idea de que son indiferentes a sus cuerpos y al mundo en el que se mueven. Son los bohemios de las computadoras, programadores compulsivos... (Estallo, 1997).

La imagen que el profesor Weizenbaum dibuja de los primeros programadores se acerca más a la de las víctimas de los relatos de vampiros, donde una voluntad fuerte y seductora les arrebata poco a poco el cuerpo alejándoles de la vida cotidiana, que a unos expertos entregados a una tarea en aquellos momentos ingente y desconocida. Es perfectamente lógico que los primeros programadores y jugadores de videojuegos necesitaran de muchas más horas delante de los ordenadores que los usuarios actuales. Eran pioneros que estaban creando sistemas, disciplinas e innovaciones en entornos aún no muy desarrollados. El desarrollo de videojuegos en los años ochenta era una labor casi casera, realizada en solitario o entre un reducido grupo de colaboradores en la habitación de estudio del domicilio familiar o en el garaje, tal y como la prototípica imagen del espacio de los inventores norteamericanos nos ha mostrado. La arquitectura abierta de ordenadores y programas permitía que los jugadores con conocimientos de programación pudieran alterar un juego que llegara a sus manos, siendo más interesante la modificación creativa que el juego en sí mismo. Hoy por hoy la industria de la informática y del videojuego es una estructura altamente cualificada donde programadores y creadores están claramente diferenciados de los usuarios, consumidores de un producto que se vende por millones y que para ser utilizado no es necesario ningún conocimiento específico que hagan de los videojugadores seres cercanos a una secta especial.

Con el tiempo y la expansión de la industria informática y los puestos de trabajo que ha generado su uso, la imagen del programador se ha desprendido de este malditismo más cercano a la obsesión del doctor Jekyll que a la cotidianeidad de una tarea regulada. Tan fecunda fue la aureola vampírica de los videojuegos que no en 
vano uno de los primeros y más populares videojuegos el Pac-Man, fue llamado en nuestro país despectivamente comecocos.

De la divulgación de los supuestos efectos de los videojuegos se han encargado en buena medida los medios de comunicación. Las noticias que difunden del mundo del videojuego muestran la mayor parte de las veces supuestos problemas que generan su uso sin que tales informaciones estén corroboradas por investigaciones científicas.

A partir de esta sombra de duda se suceden las noticias y afirmaciones alarmistas aduciendo ejemplos que rayan en lo inverosímil. En 1992 se presentó el caso de un niño italiano de siete años que había sido curado de una adicción a los videojuegos. Por primera vez se identificaba el nombre de esta nueva patología: videohipertesia. El niño pasaba varias horas delante de la pantalla y según los periodistas se le atrofió una parte del cerebro quedando en estado hipnótico. Otro de los trastornos que se han asociado con el exceso de exposición a las imágenes del monitor es la epilepsia. El parpadeo de la pantalla podría ser el causante de crisis convulsivas en los niños. Ni que decir tiene que estas afirmaciones no se basan en ningún estudio científico que asocie la permanencia delante de la pantalla durante periodos prolongados a trastornos ya existentes como la epilepsia o se creen nuevos como la citada videohipertesia. Las supuestas patologías que provoca el videojuego se encuadran dentro de un marco más amplio de temor a tecnologías afines como la también llamada Netdependencia, la adicción a internet, los chats y la navegación compulsiva. Como ejemplo baste citar los casos que el profesor Cantelmi, de la Universidad Católica Gregoriana de Roma, presentó en el Congreso de la Asociación para la Investigación de las Ciencias Neuropsiquiátricas celebrado en Roma en 1998. Según el profesor se puede decir que alguien está intoxicado por internet cuando pasa más de diez horas continuas navegando, come y duerme poco, se obsesiona por el correo electrónico, abandona las relacione sociales, afectivas y hasta el trabajo. Como en toda adicción, la abstinencia provoca un síndrome que se caracteriza por una agitación constante de los dedos que buscan el ratón, se tienen fantasías y sueños con la red.

\section{Conclusiones}

Este breve repaso por las fuentes de las utopías y distopías de los medios digitales nos ha revelado que la más avanzada tecnología sigue reviviendo viejas concepciones sobre los modelos e instrumentos de cono- cimiento. El desprestigio de la ficción vuelve a aparecer cuando las corrientes despectivas sobre el simulacro se proyectan sobre los supuestos peligros de la realidad virtual. El campo semántico que asocia drogas, 
experiencias visionarias y místicas con la dependencia y a la posesión se proyecta sobre el videojuego y los metaversos, dificultando cualquier asomo de positividad. En sentido opuesto, utópico, la tecnología como liberadora del modelo jerárquico de educación, de conocimiento, heredado de las teorías del hipertexto y la deconstrucción del relato, glorifican la autonomía del lector y por conclusión del estudiante.

Este panorama nos permite arrojar tres claras conclusiones:

- Las tecnofantasías sobre la utilización educativa de los medios digitales siguen atravesadas por tensiones fundamentales de nuestra cultura.

- Los medios digitales renuevan la ancestral corriente antimimética de Platón, que todavía fundamenta el desprestigio de la ficción como herramienta educativa.
- Tanto la utopía (libro viviente) como la distopía (videojuegos y mundos virtuales) comparten la ilusión de pérdida de la mediación. Y decimos ilusión porque es evidente que lo que se produce es un borrado de las huellas de esa mediación, no su ingenua y utópica desaparición.

Al hilo de esta última conclusión podemos formular varios interrogantes que pueden servir de motor para futuras investigaciones: ¿qué papel juega un educador en la utopía del aprendizaje autónomo? Y ¿cómo se ocultan / muestran las huellas de una nueva mediación y jerarquía de conocimiento en medios digitales que sin embargo construyen esa ilusión de libertad y acceso potencialmente ilimitado del conocimiento? ¿Cómo las utopías y distopías se utilizan con fines industriales o institucionales?

\section{Referencias}

ALSINA, P. (2010). De la digitalización de la cultura a la cultura digital, en Digithum, 12, 1-2.

CASTORIADIS, C. (1993). El mundo fragmentado. Buenos Aires, Altamira.

CONTRERAS, F. (2001). La violencia en el discurso de los nuevos medios (Televisión, videojuegos y cibercultura) en IMBERT, G. (ed.). Televisión y cotidianeidad. La función social de la televisión en el nuevo Milenio. Recuperado (5, 1, 2011), de http: / / www.um.es/tic/Documentos/MATERIAL ES/GImber2.doc

ECO, U. (2004). Apocalípticos e integrados. Barcelona: DeBolsillo.
ESTALLO, J. A. Psicopatología y videojuegos. Institut Psiquiàtric. Departamento de psicología. 1997. Recuperado (5, 1, 2011), de http: / /www.ub.es/personal/videoju.htm

FARRAY, J., AGUILAR, V., BONNY, A. y CALVO, Ma L. (2002). Videojuegos: instrumento de cultura vs cultura de la tortura. En FARRAY CUEVAS, J. (ed.): Cultura y educación en la sociedad de la información. La Coruña, Netbiblo.

GIBSON, W. (2002). Neuromante. Barcelona, Minotauro.

IHDE, D. (2004). Los cuerpos en la tecnología. Nuevas tecnologías: nuevas ideas acerca de nuestro cuerpo.

Barcelona, Editorial UOC. 
LANDOW, G. (1992). Hipertexto. Barcelona, Ediciones Paidós.

NELSON, T. (1992). Liteary machines. Sausalito, Mindful Press.

NIETZSCHE, F.(1997). El nacimiento de la tragedia. Madrid, Edaf.

RHEINGOLD, H. (1994). Realidad virtual. Los mundos artificiales generados por ordenador que modificarán nuestras vidas. Madrid, Gedisa.

SCHAEFFER, J. (2002). ¿Por qué la ficción?. Madrid, Ediciones Lengua de Trapo.

STEPHENSON, N. (1997). La era del diamante: manual ilustrado para jovencitas. Barcelona, Ediciones B.
THORNTON CALDWELL, J. (ed.) (2000). Electronic Media and Technoculture. Nueva Jersey, Rutgers University Press.

VIRILO, P. (1997). El cibermundo, la política de lo peor. Madrid, Cátedra.

WALCZAK, D. (2002). Encompassing eduaction. En Visions: Transforming Education and Training Through Advanced. Recuperado (5, 1, 2011), de http://www.ait.org.tw/infousa/enus/education/o verview/docs/2020visions.pdf

WEIZENBAUM, J. (1976). Computer Power and Human Reason. San Francisco, W.H. Freeman.

${ }^{\mathrm{i}}$ La Asociación Española de Distribuidores y Editores de Software de Entretenimiento (Adese) impulsó en al año 2000 (al igual que en EE UU se identifican desde 1994 a los videojuegos con los descriptores de la ESRB Entertainment Software Rating Board) la incorporación a los videojuegos de una etiqueta en la que se informara de la edad para la que está recomendada el juego y de unos símbolos que alertaran sobre los contenidos potencialmente peligrosos. Esta etiqueta sigue los criterios de la PEGI (Pan European Game Information) Un Comité de Seguimiento, formado por miembros de la industria del cine, por padres y por la Plataforma de Agrupaciones de la Infancia, vigilará que la clasificación se ajuste a los contenidos del software y que todas las cajas indiquen claramente la edad mínima recomendada. Para establecerla, las empresas han creado, con la colaboración de expertos, un cuestionario con 35 supuestos que les permitirá definir si el producto es para todos los públicos o para mayores de 13, 16 o 18 años. Si muestra desnudos, escenas de humillación, sangre o vísceras será para mayores de 13 años. Si además de esto incluye blasfemias, tacos o fomenta el tabaco o el alcohol, para mayores de 16, y si contiene imágenes de sexualidad humana, o que puedan "de algún modo" estimularla, el juego quedará clasificado como para mayores de 18 años. En caso de violación del código, Adese prevé la expulsión del infractor de la asociación, y el Instituto Nacional de Consumo la divulgación de su nombre para que pueda ser conocido por todos los compradores. 